\title{
Implementasi QR Code Pada Pembuatan KRS Mahasiswa di Jurusan Teknik Elektro Politeknik Negeri Ambon
}

\author{
Sri Widyanti Ginting, Eka Adhitya Dharmawan
}

\begin{abstract}
Abstrak-- Kartu Mahasiswa merupakan kartu identitas mahasiswa disebuah perguruan tinggi. Kartu mahasiswa mempunyai banyak fungsi, antara lain digunakan untuk absensi, untuk mengakses perpustakaan, Quick Response (QR) Code dapat dibuat suatu aplikasi penyandian dan pengekstrak data yang dapat membantu mempercepat proses pengambilan Daftar Nilai Semester (DNSDengan QR Code, informasi yang ada pada kartu mahasiswa dapat digunakan dengan cepat tanpa harus mengetik data satu persatu sehingga mempercepat dan mempermudah proses pengambilan Daftar Nilai Semester (DNS). Implementasi QR Code pada Kartu Mahasiswa ini sangatlah berguna bagi pegawai jurusan dan mahasiswa dalam proses pengambilan Daftar Nilai Mahasiswa agar tidak perlu lagi mengetik dan memasukan data-data mahasiswa dan nilainilai mahasiswa yang sangat banyak, maka dari itu dengan aplikasi ini para administrator kampus tinggal men-scan QR Kode Mahasiswa yang sudah terdaftar didalam aplikasi ini untuk memproses DNS yang akan diambil. Dengan begitu aplikasi ini membuat pekerjaan menjadi lebih cepat dari yang tadi-tadinya memakan waktu yang lama untuk melakukan pengisian data-data dari nama sampai pada nilai-nilai matakuliah.
\end{abstract}

Kata Kunci-Daftar Nilai Semester,QR Code, Kartu Mahasiswa

\section{Pendahuluan}

$\mathrm{K}$ artu Mahasiswa merupakan kartu identitas mahasiswa disebuah perguruan tinggi. Kartu mahasiswa mempunyai banyak fungsi, antara lain digunakan untuk absensi, untuk mengakses perpustakaan, serta kartu diskon di toko-toko tertentu. Namun pada penggunaan di Politeknik Negeri Ambon kartu mahasiswa belum dapat berfungsi maksimal karena fasilitas penunjang dalam penggunaan kartu mahasiswa masih kurang memadai.

Data yang dicetak pada kartu mahasiswa di Politeknik Negeri Ambon adalah nama mahasiswa, foto dan NIM (Nomor Induk Mahasiswa). Untuk NIM bila di-generate menjadi $Q R$ Code maka akan memudahkan dan mempercepat proses verifikasi data pada saat mahasiswa meggunakan kartunya (untuk pengambilan DNS, mengakses perpustakaan, dll), tetapi hal tersebut belum dilakukan sehingga membuat proses administrasi atau hal hal yang bersangkutan dengan mahasiswa menjadi lambat.

Quick Response (QR) Code dapat dibuat suatu aplikasi penyandian dan pengekstrak data yang dapat membantu mempercepat proses pengambilan Daftar Nilai Semester (DNS). QR Code reader dan generator merupakan perangkat lunak yang beredar bebas, sehingga semua orang dapat membuat dan memindai

\footnotetext{
Sri Widyanti Ginting adalah pengajar di Program Studi Teknik Elektro Politeknik Negeri Ambon, email widyapolnamamq@gmail.com
}

sebuah $Q R$ Code, sehingga praktik pemalsuan masih dapat dilakukan terhadap konten $Q R$ Code. Maka perlu dilakukan proses enkripsi konten sebelum diubah menjadi $Q R$ Code. Tujuan enkripsi adalah untuk konten yang diubah ke dalam $Q R$ Code tidak dapat diidentifikasi secara langsung format dan isinya oleh orang lain. $Q R$ Code mampu menyimpan semua jenis data, seperti data angka/numerik, alpa numerik, biner, kanji/kana. Selain itu $Q R$ Code memiliki tampilan yang lebih kecil daripada barcode. Hal ini dikarenakan $Q R$ Code mampu menampung data secara horizontal dan vertikal, jadi secara otomatis ukuran dari tampilannya gambar $Q R$ Code bisa hanya sepersepuluh dari ukuran sebuah barcode. Tidak hanya itu, $Q R$ Code juga tahan terhadap kerusakan, sebab $Q R$ Code mampu memperbaiki kesalahan sampai dengan 30\% tergantung dengan ukuran atau versinya, walaupun sebagian simbol QR Code kotor ataupun rusak, data tetap dapat disimpan dan dibaca. Tiga tanda berbentuk persegi di tiga sudut memiliki fungsi agar simbol dapat dibaca dengan hasil yang sama dari sudut manapun. Untuk mengantisipasi terjadinya praktik pemalsuan dokumen, maka dilakukan pengamanan dengan cara menyisipsikan suatu objek pengenal seperti nama pemilik, ID, atau tanda tangan yang digunakan untuk mencocokkan konten yang tertulis pada dokumen, yang kemudian akan disisipkan dan diproses sedemikian rupa menjadi sebuah kode yang akan diidentifikasi dan dicocokkan.

QR Code merupakan teknik yang mengubah data tertulis menjadi kode-kode 2 dimensi yang tercetak kedalam suatu media yang lebih ringkas. Dengan QR Code, informasi yang ada pada kartu mahasiswa dapat digunakan dengan cepat tanpa harus mengetik data satu persatu sehingga mempercepat dan mempermudah proses pengambilan Daftar Nilai Semester (DNS).

Berdasarkan kondisi yang dijabarkan diatas, maka penulis membuat suatu aplikasi untuk membantu pegawai di bagian kemahasiswaan untuk meminimalisir waktu dan pekerjaan dalam rangka peningkatan kinerja dalam melayani mahasiswa.

\section{TINJAUAN PUSTAKA}

\subsection{Quick Response Code}

Quick Response Code sering di sebut $Q R$ Code atau Kode QR adalah semacam simbol dua dimensi yang dikembangkan oleh Denso Wave yang merupakan anak perusahaan dari Toyota sebuah perusahaan Jepang pada tahun 1994[3]. Tujuan dari QR Kode ini adalah untuk menyampaikan informasi secara cepat dan juga mendapat tanggapan secara cepat. Pada awalnya $Q R$

Eka A Dharmawan adalah pengajar di Program Studi Teknik Informatika Jurusan Teknik Elektro Politeknik Negeri Ambon, email : eadpolnam@gmail.com 
Code digunakan untuk pelacakan bagian kendaraan untuk manufacturing. Namun sekarang, telah digunakan untuk komersil yang ditujukan pada pengguna telepon seluler. $Q R$ Code adalah perkembangan dari barcode atau kode batang yang hanya mampu menyimpan informasi secara horizontal sedangkan $Q R$ Code mampu menyimpan informasi lebih banyak, baik secara horizontal maupun vertikal.

$Q R$ Code biasanya berbentuk persegi putih kecil dengan bentuk geometris hitam (dapat dilihat di gambar 2.1), meskipun sekarang banyak yang telah berwarna dan digunakan sebagai brand produk. Informasi yang dikodekan dalam $Q R$ Code dapat berupa URL, nomor telepon, pesan SMS, V-Card, atau teks apapun (Ashford, 2010). $Q R$ Code telah mendapatkan standarisasi internasional ISO/IEC18004 dan Jepang JIS-X-0510 [3]

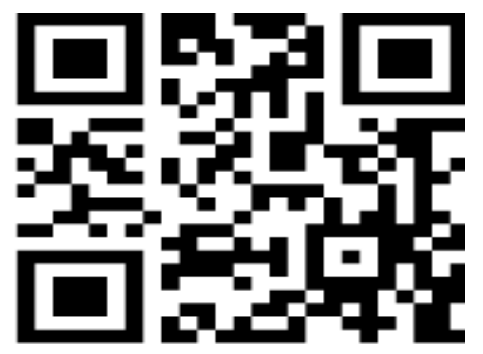

Gambar 1 Contoh QR Code

\subsection{Anatomi QR Code}

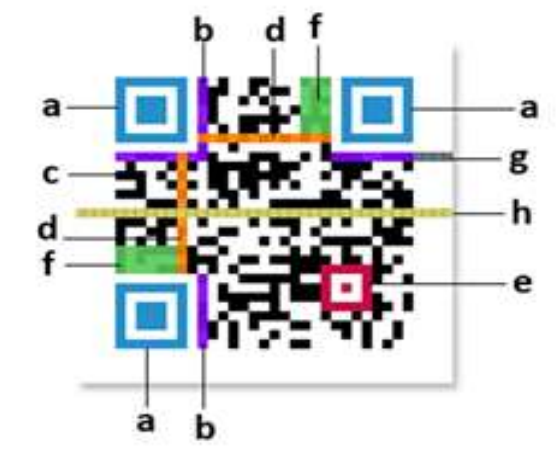

Gambar 2. Anatomi QR Code [1]

Beberapa penjelasan anatomi QR Code antara lain [1] : a.Finder Pattern berfungsi untuk identifikasi letak QR Code.

b.Format Information berfungsi untuk informasi tentang error correction level dan mask pattern.

c.Data berfungsi untuk menyimpan data yang dikodekan. d.Timing Pattern merupakan pola yang berfungsi untuk identifikasi koordinat pusat QR Code, berbentuk modul hitam putih.

e.Alignment Pattern merupakan pola yang berfungsi memperbaiki penyimpangan QR Code terutama distorsi non linier.
f.Version Information adalah versi dari sebuah QR Code. g.Quiet Zone merupakan daerah kosong di bagian terluar QR Code yang mempermudah mengenali pengenalan QR oleh sensor CCD.

h.QR Code version adalah versi dari QR Code yang digunakan.

\subsection{Mengoreksi kesalahan QR Code}

QR Code mampu mengoreksi kesalahan dan pengembalian data dalam pembacaan kode apabila qr code kotor atau rusak. Menurut Denso [3], Ada 4 tingkatan koreksi kesalahan dalam QR code :

TABEL I.

LEVEL KOREKSI. [4]

\begin{tabular}{cc}
\hline \hline $\begin{array}{c}\text { Level Koreksi } \\
\text { Kesalahan }\end{array}$ & $\begin{array}{c}\text { Jumlah Perkiraan } \\
\text { Koreksi }\end{array}$ \\
\hline L & $7 \%$ \\
M & $15 \%$ \\
Q & $25 \%$ \\
H & $30 \%$ \\
\hline \hline
\end{tabular}

Semakin tinggi tingkat koreksi kesalahan semakin besar juga versi qr code. Faktor lokasi dan lingkungan operasi perlu di timbangkan dalam menentukan level QR Code. Level $\mathrm{Q}$ dan $\mathrm{H}$ baik digunakan di pabrik yang kotor, sedangkan L untuk tempat yang bersih. Level yang sering digunakan adalah level $\mathrm{M}$ dengan perkiraan koreksi mencapai $15 \%$.

\subsection{Manfaat QR code}

Beberapa manfaat yang terdapat pada QR Code antara lain [3] :

a. Kapasitas tinggi dalam menyimpan data

Sebuah QR Code tunggal dapat menyimpan sampai 7.089 angka.

b. Ukuran yang kecil

Sebuah QR Code dapat menyimpan jumlah data yang sama dengan barcode 1D dan tidak memerlukan ruang besar.

c. Dapat mengoreksi kesalahan

Tergantung pada tingkat koreksi kesalahan yang dipilih, data pada QR code yang kotor atau rusak sampai 30\% dapat diterjemahkan dengan baik.

d. Banyak jenis data

QR Code dapat menangani angka, abjad, simbol, karakter bahasa Jepang, Cina atau Korea dan data biner.

e. Kompensasi distorsi

QR Code tetap dapat dibaca pada permukaan melengkung atau terdistorsi.

f. Kemampuan menghubungkan

Sebuah QR Code dapat dibagi hingga 16 simbol yang lebih kecil agar sesuai dengan ruang. Simbol-simbol kecil yang dibaca sebagai kode tunggal apabila di scan menurut urutan. 


\subsection{Kriptografi}

Kriptografi adalah ilmu yang mempelajari mengenai bagaimana cara mengamankan suatu informasi. Pengamanan ini dilakukan dengan mengenkrip informasi tersebut dengan suatu kunci khusus. Informasi ini sebelum dienkrip dinamakan plaintext. Setelah dienkrip dengan suatu kunci dinamakan ciphertext. Ada empat tujuan mendasar dari ilmu kriptografi ini yang juga merupakan aspek keamanan informasi yaitu :

1. Kerahasiaan, adalah layanan yang digunakan untuk menjaga isi dari informasi dari siapapun kecuali yang memiliki otoritas atau kunci rahasia untuk membuka/mengupas informasi yang telah disandi.

2. Integritas data, adalah berhubungan dengan penjagaan dari perubahan data secara tidak sah. Untuk menjaga integritas data, sistem harus memiliki kemampuan untuk mendeteksi manipulasi data oleh pihak-pihak yang tidak berhak, antara lain penyisipan, penghapusan, dan pensubsitusian data lain kedalam data yang sebenarnya.

3. Autentikasi, adalah berhubungan dengan identifikasi/pengenalan, baik secara kesatuan sistem maupun informasi itu sendiri. Dua pihak yang saling berkomunikasi harus saling memperkenalkan diri. Informasi yang dikirimkan melalui kanal harus diautentikasi keaslian, isi datanya, waktu pengiriman, dan lain-lain.

4. Non-repudiasi., adalah usaha untuk mencegah terjadinya penyangkalan terhadap pengiriman/terciptanya suatu informasi oleh yang mengirimkan/membuat. Istilah-istilah yang digunakan dalam bidang kriptografi :

a. Plaintext (M) adalah pesan yang hendak dikirimkan (berisi data asli).

b. Ciphertext (C) adalah pesan ter-enkrip (tersandi) yang merupakan hasil enkripsi.

c. Enkripsi (fungsi E) adalah proses pengubahan plaintext menjadi ciphertext.

d. Dekripsi (fungsi D) adalah kebalikan dari enkripsi yakni mengubah ciphertext menjadi plaintext, sehingga berupa data awal/asli. [3]

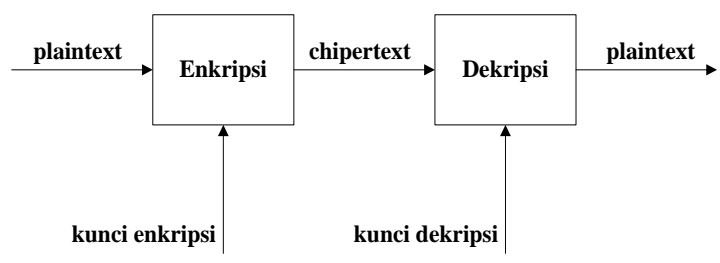

Gambar 2. Diagram Proses Enkripsi Dan Deskripsi. [5]

\subsection{PHP}

PHP adalah singkatan dari "PHP: Hypertext Prepocessor", yaitu bahasa pemrograman yang digunakan secara luas untuk penanganan pembuatan dan pengembangan sebuah situs web dan bisa digunakan bersamaan dengan HTML. PHP diciptakan oleh Rasmus Lerdorf pertama kali tahun 1994. Pada awalnya PHP adalah singkatan dari "Personal Home Page Tools". Selanjutnya diganti menjadi FI ("Forms Interpreter"). Sejak versi 3.0, nama bahasa ini diubah menjadi "PHP: Hypertext Prepocessor" dengan singkatannya "PHP". PHP versi terbaru adalah versi ke-5. Berdasarkan survey Netcraft pada bulan Desember 1999, lebih dari sejuta website menggunakan PHP, di antaranya adalah NASA, Mitsubishi, dan RedHat.

\subsection{MYSQL}

MySQL adalah sebuah perangkat lunak system manajemen basis data SQL (DBMS) yang multithread, dan multi-user [. MySQL adalah implementasi dari system manajemen basisdata relasional (RDBMS). MySQL dibuah oleh TcX dan telah dipercaya mengelola system dengan 40 buah database berisi 10.000 tabel dan 500 di antaranya memiliki 7 juta baris [7]. MySQL AB merupakan perusahaan komersial Swedia yang mensponsori dan yang memiliki MySQL. Pendiri MySQL AB adalah dua orang Swedia yang bernama David Axmark, Allan Larsson dan satu orang Finlandia bernama Michael "Monty". Setiap pengguna MySQL dapat menggunakannya secara bebas yang didistribusikan gratis dibawah lisensi GPL(General Public License) namun tidak boleh menjadikan produk turunan yang bersifat komersial.

\subsection{CI ( CODEIGNITER )}

CodeIgniter adalah sebuah framework berbasis PHP yang kuat dengan footprint yang sangat kecil, dibangun untuk pengembang yang membutuhkan toolkit sederhana dan elegan untuk membuat aplikasi web dengan fitur lengkap. CodeIgniter pertama kali ditulis oleh Rick Ellis (http://www.ellislab.com), seorang musisi rock yang beralih profesi menjadi programmer dalam riset kecilkecilannya dan menghasilkan suatu framework PHP yang berukuran kecil, ringan serta memenuhi fitur umum aplikasi PHP. Namun, sejak tahun 2014 CodeIgniter telah dimiliki oleh British Columbia Institute of Technology (BCIT). Segala hal mengenai CodeIgniter dapat ditemui di websiter resminya beralamatkan http://www.codeigniter.com. Untuk saat ini telah merilis versi 3.0.6.

CodeIgniter adalah sebuah kerangka kerja yang berisi berbagai fungsi yang dapat digunakan untuk membuat fungsi-fungsi yang kompleks. Dalam membangun sebuah web, biasanya berkutat pada script koneksi database, pagination, proses login, query database. Dengan menggunakan sebuah framework CodeIgniter, tidak perlu lagi menuliskan perintah mysql_connect, myql_select_db atau semacamnya, karena CodeIgniter sudah menyediakan semua itu. Kita hanya perlu tau bagaimana cara menggunakannya.[4]

\subsection{HTML}

HTML adalah bahasa markup internet (web) berupa kode dan simbol yang dimasukkan kedalam sebuah file yang ditujukan untuk ditampilkan didalam sebuah 
website. Website yang dibuat dengan HTML ini, dapat dilihat oleh semua orang yang terkoneksi dengan internet [3]. Tentunya dengan menggunakan aplikasi penjelajah internet (browser) seperti Internet Explorer, Mozilla Firefox dan Google Chrome. Language yang berarti bahasa. HTML adalah sebuah bahasa, yang memiliki kata kata berupa kode dan syntax seperti bahasa yang lain. Saat ini bahasa HTML masih terus dikembangkan Hal ini dikarenakan pengguna internet semakin hari semakin berkembang pesat. Oleh karena itu bahasa HTML harus ditingkatkan lagi agar bisa menciptakan halaman web yang lebih berkualitas. Untuk itulah dibentuk sebuah organisasi yang bertanggungjawab mengembangkan bahasa HTML.

\section{METODE PENELITIAN}

\subsection{Lokasi Penelitian}

Penelitian ini dilakukan pada Politeknik Negeri Ambon.

\subsection{Metode Penelitian}

Metode yang digunakan dalam menyelesaikan penelitian adalah metode Research dan Development (riset dan Pengembangan), yaitu suatu metode yang dipakai untuk mengembangkan model, alat atau aplikasi tertentu berdasarkan proses penelitian.

\subsection{Teknik Pengumpulan Data}

Ada beberapa teknik pengumpulan data, yaitu wawancara, kuesioner, observasi, dan studi dokumentasi. Pada pengumpulan data tetap mengacu pada parameter dan sesuai dengan kebutuhan analisis sistem. Adapun pengumpulan data yag dilakukan adalah sebagai berikut;

1. Wawancara

Wawancara dilakukan dalam bentuk tanya jawab kepada bagian akademik dilingkungan Politeknik Negeri Ambon, sebagai pihak yang berwenang.

2. Observasi

Observasi merupakan metode pengumpulan data dengan cara mencatat semua hasil pengamatan dan informasi yang diperoleh selama penelitian berlangsung.

3. Studi Dokumentasi

Teknik pengumpulan data dengan cara mempelajari beberapa dokumen, literature yang ada hubungannya dengan masalah penelitian.

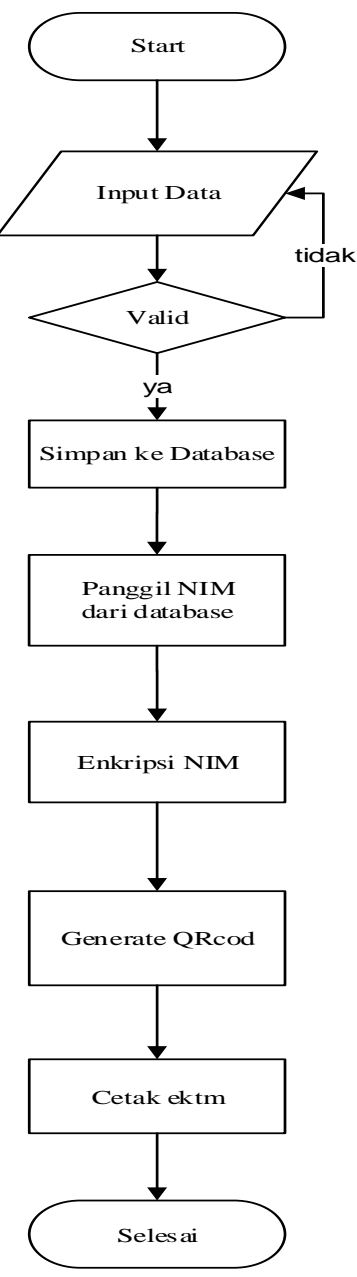

Gambar 3. Flowchart Penyimpanan data ke QR Code (Encoder)

Pada Gambar 3 merupakan flowchart Encoder, dengan penjelasan sebagai berikut : mulai, menginput data ketika data tidak valid harus diulang sampai data valid dan dilanjutkan dengan menyimpan data dalam database dan di enkripsi kemudian melakukan pembangkitan QR Code dan dicocokkan dengan data semula ketika data cocok maka proses cetak ektm dilakukan.

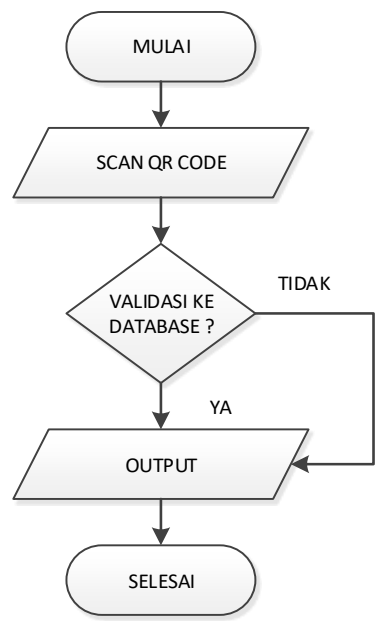

Gambar 4. Flowchart Pengambilan Data dari QR (Decoder) 
Pada gambar 4 flowchart menggambarkan alur Decoder atau proses pengambilan data dari $Q R$ Code.

\subsection{Data Flow Diagram (DFD)}

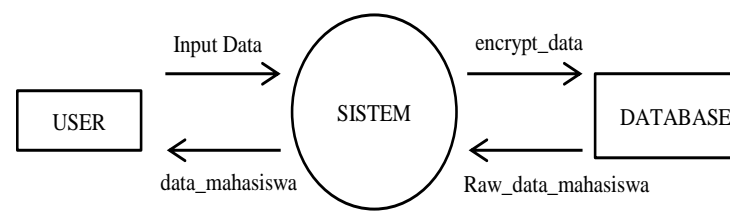

Gambar 5. Data Flow Diagram Level 1

DFD pada gambar 5 menjelaskan bahwa alur sistem pada saat user menginput data mahasiswa kemudian akan di enkripsi dan disimpan pada database, kemudian ketika data diambil dari database akan di tampilkan setelah di deskripsi sehingga user dapat melihat data secara utuh dengan kata lain tidak acak.

\section{HASIL DAN PEMBAHASAN}

Setelah melakukan perancangan desain dan antarmuka program pada aplikasi Kartu Mahasiswa menggunakan $Q R$ Code, maka hasil dari aplikasi yang dimaksud seperti berikut dibawah ini.

1. Halaman Dashboard

Halaman dashboard dalam aplikasi berisi menu data mahasiswa, data mata kuliah, daftar nilai semester, dimana akan dipakai untuk mengolah data DNS mahasiswa yaitu memasukkan data DNS mahasiswa dan mencetaknya

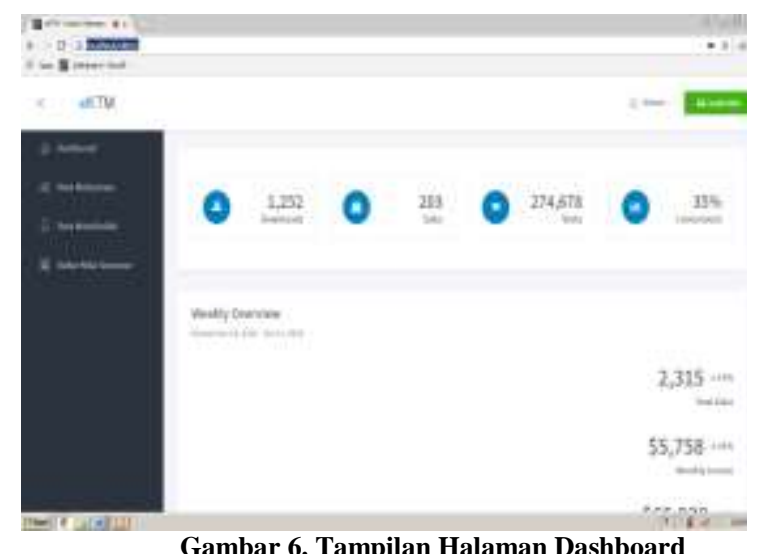

2. Tampilan Halaman Data Mahasiswa berisi tentang data mahasiswa berupa NIM, Nama, Jenis Kelamin dan Semester.

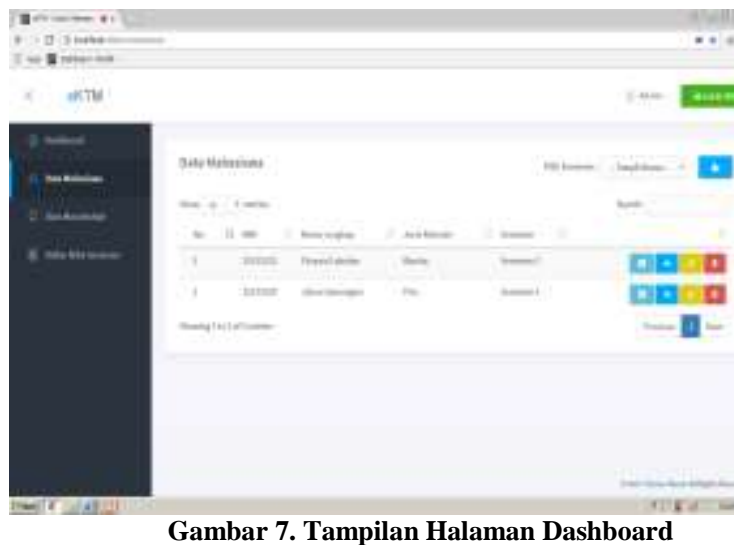

3. Tampilan Halaman Data Mata Kuliah yang berisi tentang Kode Mata kuliah yang dipakai sebagai ID atau pengenal Nama mata kuliah pada aplikasi, dan Nama mata kuliah berdasarkan kode matakuliah yang dimasukan.

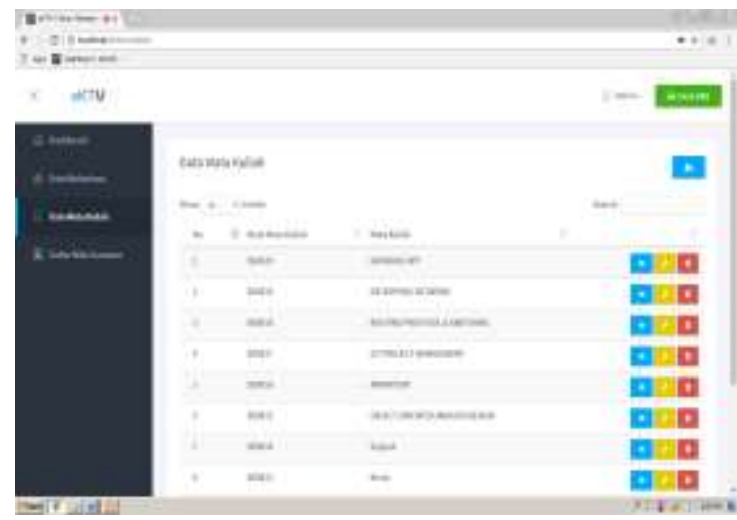

Gambar 8. Tampilan Halaman Dashboard

4. Halaman Data Nilai Semester

Tampilan halaman data nilai semester, yang berisi tentang Id Mata Kuliah, Id Mahasiswa dan Nilai yang akan digunakan untuk mencetak DNS berdasarkan nilai yang didapat dari masing-masing mata kuliah

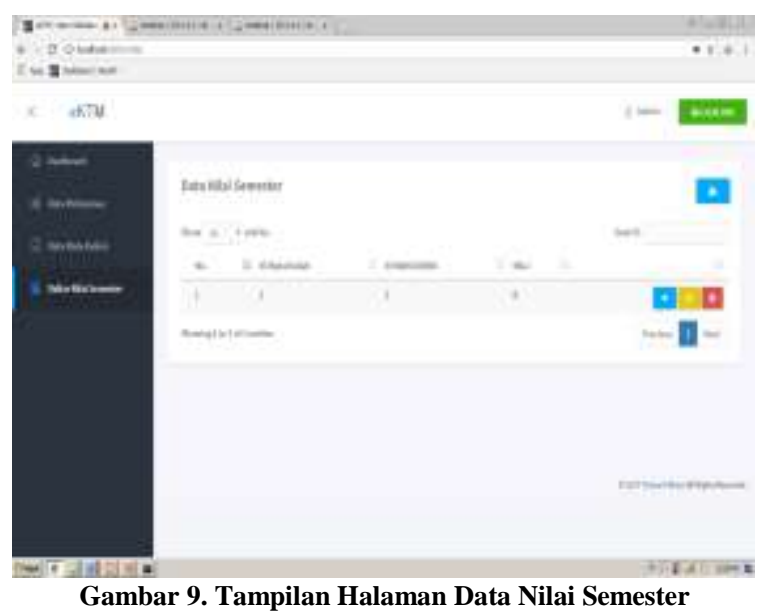




\section{Tampilan Scanner e-KTM}

Pada tampilan scanner e-KTM akan digunakan untuk men-scan $Q R$ Code atau identitas dari DNS tersebut untuk dicetak tanpa harus membuat DNS mahasiswa yang bersangkutan, karena pada saat men-scan $Q R$ Code tersebut maka secara otomatis DNS sudah terbentuk dari data-data yang ada didalam aplikasi tersebut.

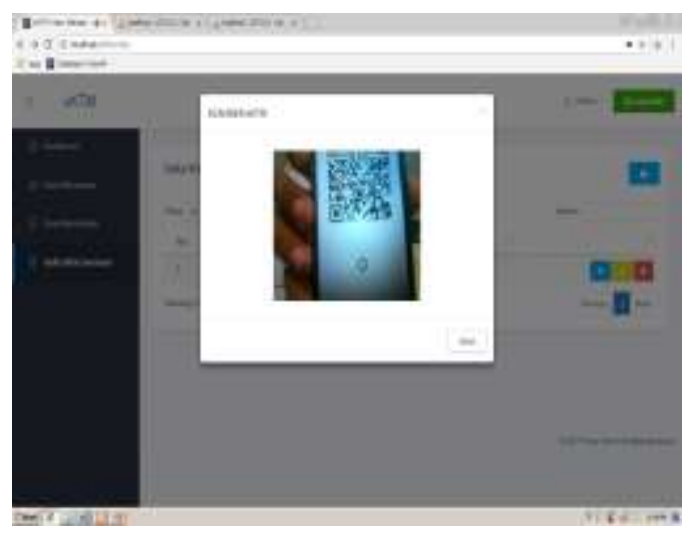

Gambar 10. Tampilan Scanner QR Code e-KTM

\section{KESIMPULAN DAN SARAN}

\section{A. Kesimpulan}

Dari hasil perancangan sistem kemudian dilanjutkan dengan pengambilan data, pengujian dan analisa, maka dapat disimpulkan sebagai berikut : aplikasi QR Code pada kartu mahasiswa berguna bagi pegawai jurusan dan mahasiswa dalam proses pengambilan Daftar Nilai Mahasiswa agar tidak perlu lagi mengetik dan memasukan data-data dan nilai.

\section{B. Saran}

Diharapkan pengembangan sistem kedepan dapat dilengkapi dengan sistem keamanan yang lebih baik dan juga dapat dikembangkan dengan sistem yang terhubung secara online. Sehingga dapat mengefisiensi waktu dan kinerja pegawai dibagian kemahasiswaan.

\section{DAFTAR PUSTAKA}

[1] Adha, Ripandy. 2010. Message Digest dalam bentuk QR Code Sebagai Tanda Tangan Digital. Bandung: Program Studi Teknik Informatika STEI ITB.

[2] Arbie, E.2000. Pengantar Sistem Informasi Manajemen. Jakarta: Bina. Alumni Indonesia

[3] Betha dan Husni. 2014. Pemrograman WEB dengan HTML. Bandung:Informatika Bandung

[4] Denso Wave. 2010. QR Code Introduction - Symbol Version. Diakses pada 25 Agustus 2017 di http://www.denso-wave.com/QRCode/QRgene2e.html

[5] Dewi Rosmala dkk. 2011. Komparasi Framework Mvc(Codeigniter, Dan Cakephp) Pada Aplikasi Berbasis WEB/Jurnal Informatika No.2, Vol. 2, Mei-Agustus 2011.

[6] Fairuzabadi, M. 2010. Implementasi Kriptografi Klasik Menggunakan Borland Delphi. Jurnal Dinamika Informatika, Vol 4

[7] Kadir, Abdul. 2013. Pemrograman Database MySQL Untuk Pemula. Yogyakarta:Mediakom

[8] Kendall, K.E., Kendall J.E. 2003. Analisis dan Perancangan Sistem Jilid 1. Prehallindo. Jakarta

[9] Herlambang, S dan Tanuwijaya, H. 2005. Sistem Informasi: konsep, teknologi, dan manajemen. Graha ilmu, Yogyakarta. 